\title{
AUTHOR INDEX FOR VOLUME 101
}

AHMED, S. and LIM, M. F.; On the Euler characteristics of signed Selmer groups

ALI, E. J.; Canonical dual finite element method for solving nonconvex mechanics and topology optimisation problems

ALJUAID, M. and COLONNA, F.; On the harmonic Zygmund spaces

ALLU, V.; see GHOSH, N.

ALODAT, T.; On asymptotics of functionals of random fields with long-range dependence

ALOMARI, H. M.; Statistical analysis of long-range dependent random processes and fields

ALTAVILLA, A. and BALLICO, E.; Algebraic surfaces with infinitely many twistor lines

AN, L.; see YANG, D.

ANDERSEN, P. J.; Degree bounded geometric spanning trees with a bottleneck objective function

ARMSTRONG, B.; Simplicity of twisted $C^{*}$-algebras of topological higherrank graphs

BALLICO, E.; see ALTAVILLA, A.

BETTIO, E. and JABARA, E.; On a problem of Praeger and Schneider

BOUMAHDI, R., KIHEL, O., LARONE, J. and YADJEL, M.; A new proof of the Carlitz-Lutz theorem

BRZDEK, J. and EL-HADY, E.-S.; On approximately additive mappings in 2Banach spaces

CARNAFFAN, S.; Anomalous diffusion processes: Stochastic models and their properties

CATALANO, L. and CHANG-LEE, M.; On the connection between differential polynomial rings and polynomial rings over nil rings

CHALEBGWA, T. P.; Algebraic values of certain analytic functions defined by a canonical product

CHAMBERLAIN, R.; Subgroups with no abelian composition factors are not distinguished

CHAN, T. H.; Gaps between divisible terms in $a^{2}\left(a^{2}+1\right)$

CHANG-LEE, M.; see CATALANO, L.

CHEN, W.; see TU, Q.

CHI, Z. and SKIBA, A. N.; On a lattice characterisation of finite soluble $P S T$-groups

CHOULLI, M.; New global logarithmic stability results on the Cauchy problem for elliptic equations

CHU, W.; Symmetric functions and multiple zeta values

COLONNA, F.; see ALJUAID, M.

DAI, L. and PAN, H.; Closed forms for degenerate Bernoulli polynomials 
DOYLE, G. and WILLIAMS, K. S.; Prime-universal quadratic forms

$$
a x^{2}+b y^{2}+c z^{2} \text { and } a x^{2}+b y^{2}+c z^{2}+d w^{2}
$$

EL-HADY, E.-S.; see BRZDEK, J.

FAN, X.; Permutation polynomials of degree 8 over finite fields of odd characteristic

FENG, L.; Numerical investigation and application of fractional dynamical systems

GENEVOIS, A. and VARGHESE, O.; Conjugating automorphisms of graph products: Kazhdan's property (T) and SQ-universality

GHAHRAMANI, H.; The first cohomology group of Banach inverse semigroup algebras with coefficients in $L$-embedded Banach bimodules

488

GHOSH, N. and ALLU, V.; On some subclasses of harmonic mappings $\quad 130$

GILL, M. J. and WANLESS, I. M.; Perfect 1-factorisations of $K_{16}$

GONGOPADHYAY, K., MISHRA, M. M. and TIWARI, D.; On discreteness of subgroups of quaternionic hyperbolic isometries

283

GU, C.-Y. and GUO, V. J. W.; A $q$-analogue of a hypergeometric congruence

GUO, V. J. W.; see GU, C.-Y.

294

294

JABARA, E.; see BETTIO, E.

JENNER, A. L.; Applications of mathematical modelling in oncolytic virotherapy and immunotherapy

KEKEÇ, G.; $U$-numbers in fields of formal power series over finite fields $\quad 218$

KIHEL, O; see BOUMAHDI, R.

KLYACHKO, A. A. and PONFILENKO, A. N.; Intersections of subgroups in virtually free groups and virtually free products

KORHONEN, R.; see LIU, X.

KOZLOWSKI, W. M.; On modulated topological vector spaces and applications

KUVEKE, R. E. H.; The performance of some statistical procedures used in case-control studies and methylomics

LARONE, J.; see BOUMAHDI, R.

LEIDERMAN, A. and MORRIS, S. A.; Embeddings of free topological vector spaces

LEONETTI, P. and SANNA, C.; Directions sets: A generalisation of ratio sets

LI, R., LIN, B. L. S. and WANG, A. Y. Z.; Generalisation of a result on distinct partitions with bounded part differences

LIM, M. F.; see AHMED, S.

LIN, B. L. S.; Partitions with an arbitrary number of specified distances 35

LIN, B. L. S.; see LI, R.

LIU, D. and SUN, X.; The factorial conjecture and images of locally nilpotent derivations

LIU, X. and KORHONEN, R.; On the periodicity of transcendental entire functions

LUO, Y. F.; see ZHANG, W. T.

LV, H.; see YANG, D. 
LYDEAMORE, M. J.; Mechanistic and statistical models of skin disease transmission

MAN, S.; On a class of nonlinear Schrödinger equations on finite graphs

MISHRA, M. M.; see GONGOPADHYAY, K.

MORRIS, S. A.; see LEIDERMAN, A.

MURAHARA, H. and MURAKAMI, T.; On a generalisation of a restricted sum formula for multiple zeta values and finite multiple zeta values

MURAKAMI, T.; see MURAHARA, $\mathrm{H}$.

NGUYEN-HUY, T.; Copula-based statistical modelling of synoptic-scale climate indices for quantifying and managing agricultural risks in Australia

OMWONYLEE, J. O.; Large deviations for the longest gap in Poisson processes 146

PAN, H.; see DAI, L.

PASTECZKA, P.; Weakening of the Hardy property for means 118

PONFILENKO, A. N.; see KLYACHKO, A. A. 266

QIU, X.; see TU, Q.

RATNAYAKE, I. G.; Teaching algebra with digital technology: Factors influencing secondary mathematics teachers' task development and implementation

RICKARD, J.; A cocomplete but not complete abelian category

ROTH, J. and UPADHYAY, A.; On almost stable CMC hypersurfaces in manifolds of bounded sectional curvature

SAMART, D.; On a noncritical symmetric square $L$-value of the congruent number elliptic curves

SANNA, C.; see LEONETTI, P.

SIMONIC , A.; On Littlewood's proof of the prime number theorem

SKIBA, A. N.; see CHI, Z.

SOUTH, L.; Contributions to computational Bayesian statistics

STA ̌́, M.; On the crossing number of the join of the wheel on five vertices with the discrete graph

SUN, H.; Degree of the $W$-operator and noncrossing partitions

SUN, X.; see LIU, D.

SUN, Z.-H.; New supercongruences involving products of two binomial coefficients

TANG, H. C.; A shifted convolution sum of $d_{3}$ and the Fourier coefficients of Hecke-Maass forms II

TĂRNĂUCEANU, M.; The number of cyclic subgroups of finite abelian groups and Menon's identity

THORNTON, L.; On base radical theory in finite settings

TI, Y. B.; Isogenies of abelian varieties in cryptography

TIWARI, D.; see GONGOPADHYAY, K.

TU, Q., CHEN, W. and QIU, X.; The distributional $k$-Hessian in fractional Sobolev spaces 
VARGHESE, O.; see GENEVOIS, A.

VASKOVYCH, V.; Theory and statistics of long-range dependent random processes

WANG, A. Y. Z.; see LI, R.

WANG, Q.; see WEI, Y.

WANLESS, I. M.; see GILL, M. J.

WEI, Y., WU, B. and WANG, Q.; On the generalisation of Sidel'nikov's theorem to $q$-ary linear codes

WILLIAMS, K. S.; see DOYLE, G.

WRIGHT, T.; A conditional density for Carmichael numbers

WU, B.; see WEI, Y.

157

YADJEL, M.; see BOUMAHDI, R.

YANG, D., AN, L. and LV, H.; Finite $p$-groups all of whose nonnormal subgroups have bounded normal cores

YI, I.; Homology and Matui's HK conjecture for groupoids on one-dimensional solenoids

ZELENYUK, Y. and ZELENYUK, Y.; A Ramsey type result for Latin squares

ZELENYUK, Y.; see ZELENYUK, Y.

362

ZHANG, W. T. and LUO, Y. F.; The finite basis problem for involution semigroups of triangular $2 \times 2$ matrices 


\section{INFORMATION FOR AUTHORS}

The Bulletin of the Australian Mathematical Society aims at quick publication of original research in all branches of mathematics. To ensure speedy publication, only articles which are sufficiently well presented, able to be published without revision, and which are judged by the Editor (often in consultation with an Associate Editor) to be competitive are refereed. This policy is in the interests of authors, as a quick rejection is better than a slow rejection. The Bulletin receives more than five times the material that can be published, therefore there are many commendable papers not accepted. Editorial decisions on acceptance or otherwise are taken quickly, normally within a month of receipt of the paper. Papers are accepted only after peer review.

Manuscripts are accepted for review with the understanding that the same work is not concurrently submitted elsewhere. For a paper to be acceptable for publication, not only should it contain new and interesting results, but also

(i) the exposition should be clear and attractive, and

(ii) the manuscript should be in publishable form, without revision.

Further information regarding these requirements may be found through our website www.austms.org.au/Bulletin. Authors are asked to avoid, as far as possible, the use of mathematical symbols in the title.

Articles should be prepared in $\mathrm{ET}_{\mathrm{E}} \mathrm{X}$ using $\mathcal{A}_{\mathcal{M}} \mathcal{S}$-LTEX packages and submitted as a PDF file via our journal management system, at www.austms.org.au/Publications/Submissions/BAustMS. This permits authors to track their papers through the editorial process. Recent versions of $\mathrm{T}_{\mathrm{E}} \mathrm{X}$ are able to produce PDF files directly. A LTTEX class file for the Bulletin can be downloaded from the website. Authors who need assistance may email the secretary of the Bulletin at editor@bulletin.austms.org.au.

Authors are advised to keep copies of all files of the submitted article; the Bulletin will not accept responsibility for any loss.

\section{EDITORIAL POLICY}

1. References. Arrange references alphabetically (by surname of the first author) and cite them numerically in the text. Ensure the accuracy of the references: authors' names should appear as in the work quoted. Include in the list of references only those works cited, and avoid citing works which are in preparation or submitted. Where the work cited is not readily accessible (for example, a preprint) a copy of the article should be included with your submission.

\section{Abstracts.}

1. Each paper must include an abstract of not more than 150 words, which should contain a brief but informative summary of the contents of the paper, but no inessential details.

2. The abstract should be self-contained, but may refer to the title.

3. Specific references (by number) to a section, proposition, equation or bibliographical item should be avoided.

3. Subject Classification and Key Words. Authors should include a few key words and phrases and one or more classification numbers, following the American Mathematical Society 2010 Mathematics Subject Classification for all codes. Details of this scheme can be found on the web at www.ams.org/msc.

4. Abstracts of PhD Theses. The Bulletin endeavours to publish abstracts of all accepted Australasian $\mathrm{PhD}$ theses in mathematics. One restriction, however, is that the abstract must be received by the Editor within six months of the degree being approved.

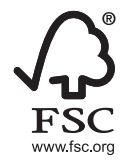

This journal issue has been printed on FSC-certified paper and cover board. FSC is an independent, non-governmental, not-for-profit organisation established to promote the responsible management of the world's forests. Please see www.fsc.org for information. 


\section{Table of Contents}

On the crossing number of the join of the wheel on five vertices with the discrete graph

Staš, $M$.

A Ramsey type result for Latin squares

Zelenyuk, $\Upsilon$. \& Zelenyuk, $Y$.

New supercongruences involving products of two binomial coefficients

Sun, Z.-H.

A conditional density for Carmichael numbers

Wright, T.

Directions sets: A generalisation of ratio sets

Leonetti, P. \& Sanna, $C$.

Gaps between divisible terms in $a^{2}\left(a^{2}+1\right)$

Chan, T. H.

A shifted convolution sum of $d_{3}$ and the Fourier coefficients of Hecke-Maass forms II

Tang, H. C.

Algebraic values of certain analytic functions defined by a canonical product

Chalebgwa, T. P.

Symmetric functions and multiple zeta values

Chu, W.

On the connection between differential polynomial rings and polynomial rings over nil rings

Catalano, L. \& Chang-Lee, $M$.

A cocomplete but not complete abelian category

Rickard, 7 .

Subgroups with no abelian composition factors are not distinguished

Chamberlain, $R$.

On the periodicity of transcendental entire functions

Liu, X. \& Korhonen, $R$.

On the harmonic Zygmund spaces

Aljuaid, M. \& Colonna, F.

On a class of nonlinear Schrödinger equations on finite graphs

Man, $S$.

The first cohomology group of Banach inverse semigroup algebras with coefficients in $L$-embedded Banach bimodules

Ghahramani, $H$.

The distributional $k$-Hessian in fractional Sobolev spaces

Tu, Q., Chen, W. \& Qiu, X.

Abstracts of $\mathrm{PhD}$ Theses

Isogenies of abelian varieties in cryptography

Ti, Y. B.

On base radical theory in finite settings

Thornton, $L$.

Simplicity of twisted $\mathrm{C} *$-algebras of topological higher-rank graphs

Armstrong, $B$.

Anomalous diffusion processes: Stochastic models and their properties

Carnaffan, $S$.

On asymptotics of functionals of random fields with long-range dependence

Alodat, T.

Applications of mathematical modelling in oncolytic virotherapy and immunotherapy

Jenner, $A$. $L$.

Author Index for Volume 101 